\title{
Effects of Moderate Alcohol Drinking in Patients with Nonalcoholic Fatty Liver Disease
}

\author{
Inbeom Kwon ${ }^{1}$, Dae Won Jun², and Jin-Hwa Moon ${ }^{3}$ \\ Departments of ${ }^{1}$ Pre-Medicine, ${ }^{2}$ Internal Medicine, and ${ }^{3}$ Pediatrics, Hanyang University College of Medicine, Seoul, Korea
}

Whether moderate alcohol intake is beneficial remains an unsolved issue. Recent studies have suggested that moderate alcohol consumption is associated with beneficial effects related to the prevention of cardiovascular diseases. Moderate alcohol consumption leads to a higher risk of hepatocellular carcinoma in patients with chronic viral liver diseases. However, the effects of moderate alcohol intake in patients with nonalcoholic fatty liver disease are unclear. In this review, we analyzed, from various perspectives, the effect of moderate alcohol consumption in patients with nonalcoholic fatty liver disease. We reviewed four cohort studies and seven cross-sectional studies. The results showed that moderate alcohol consumption was negatively related to the incidence of nonalcoholic steatohepatitis and liver fibrosis. However, moderate alcohol consumption was positively associated with the incidence of hepatocellular carcinoma in patients with nonalcoholic fatty liver disease. The results of the analysis of the relationship between moderate alcohol consumption and the levels of triglycerides, total cholesterol, high-density lipoprotein, and hypertension were diverse. More clinical data are needed to draw a conclusion about the effects of moderate alcohol consumption in patients with nonalcoholic fatty liver disease. (Gut Liver 2019;13:308314)

Key Words: Non-alcoholic fatty liver disease; Alcohol; Moderate drinking

\section{INTRODUCTION}

Alcohol is an important cause of chronic liver disease. Chronic alcohol intake aggravates most liver diseases, and moderate alcohol intake may exacerbate certain liver diseases. For example, moderate alcohol consumption ( $60 \mathrm{~g} /$ day for men and $40 \mathrm{~g} /$ day for women) in patients with hepatitis B virus infection increased the incidence of hepatocellular carcinoma (HCC) by about 1.5 -fold, ${ }^{1-4}$ although the cutoff values of alcohol intake were unclear. ${ }^{4}$

However, effects of moderate alcohol consumption in specific liver diseases are still in debate. For example, many studies examined the effects of moderate alcohol consumption in the prevalence of nonalcoholic fatty liver disease (NAFLD). In a study by Sogabe et al., ${ }^{5}$ moderate alcohol drinking of $\leq 140 \mathrm{~g} /$ wk was associated with lower prevalence of NAFLD in Japanese females. In contrast, a study by Liu et al. ${ }^{6}$ suggested moderate alcohol drinking was associated with higher prevalence of NAFLD in Chinese men. Roerecke et al. ${ }^{7}$ reviewed that moderate alcohol drinking was associated with lower prevalence of NAFLD in Japanese, but not in other countries.

Interestingly, there were some researches suggesting that nonalcoholic steatohepatitis (NASH) and liver fibrosis were negatively associated with moderate alcohol consumption in patients with NAFLD, although NAFLD is similar to alcoholic fatty liver disease and has a similar pathological physiology. ${ }^{8}$ Previously, effects of moderate alcohol drinking in NAFLD patients were reviewed by Ajmera et al. ${ }^{9}$ and Boyle et al. ${ }^{10}$ However, the effects were not summarized by specific clinical symptoms. In this review, we compared and analyzed studies investigating the effects of moderate alcohol drinking on NASH and fibrosis in patients with NAFLD.

\section{OVERVIEW OF THE EFFECT OF ALCOHOL ON NAFLD}

To date, 11 studies were available on the effects of alcohol on liver disease progression in patients with NAFLD (Table 1). Four were cohort studies, and seven were cross-sectional stud-

Correspondence to: Dae Won Jun (https://orcid.org/0000-0002-2875-6139)

Department of Internal Medicine, Hanyang University Hospital, Hanyang University College of Medicine, 222-1 Wangsimni-ro, Seongdong-gu, Seoul 04763, Korea

Tel: +82-2-2290-8338, Fax: +82-2-2298-9183, E-mail: noshin@hanyang.ac.kr

Received on April 12, 2018. Revised on June 18, 2018. Accepted on June 22, 2018. Published online October 30, 2018 pISSN 1976-2283 eISSN 2005-1212 https://doi.org/10.5009/gnl18175

(a) This is an Open Access article distributed under the terms of the Creative Commons Attribution Non-Commercial License (http://creativecommons.org/licenses/by-nc/4.0) which permits unrestricted non-commercial use, distribution, and reproduction in any medium, provided the original work is properly cited. 


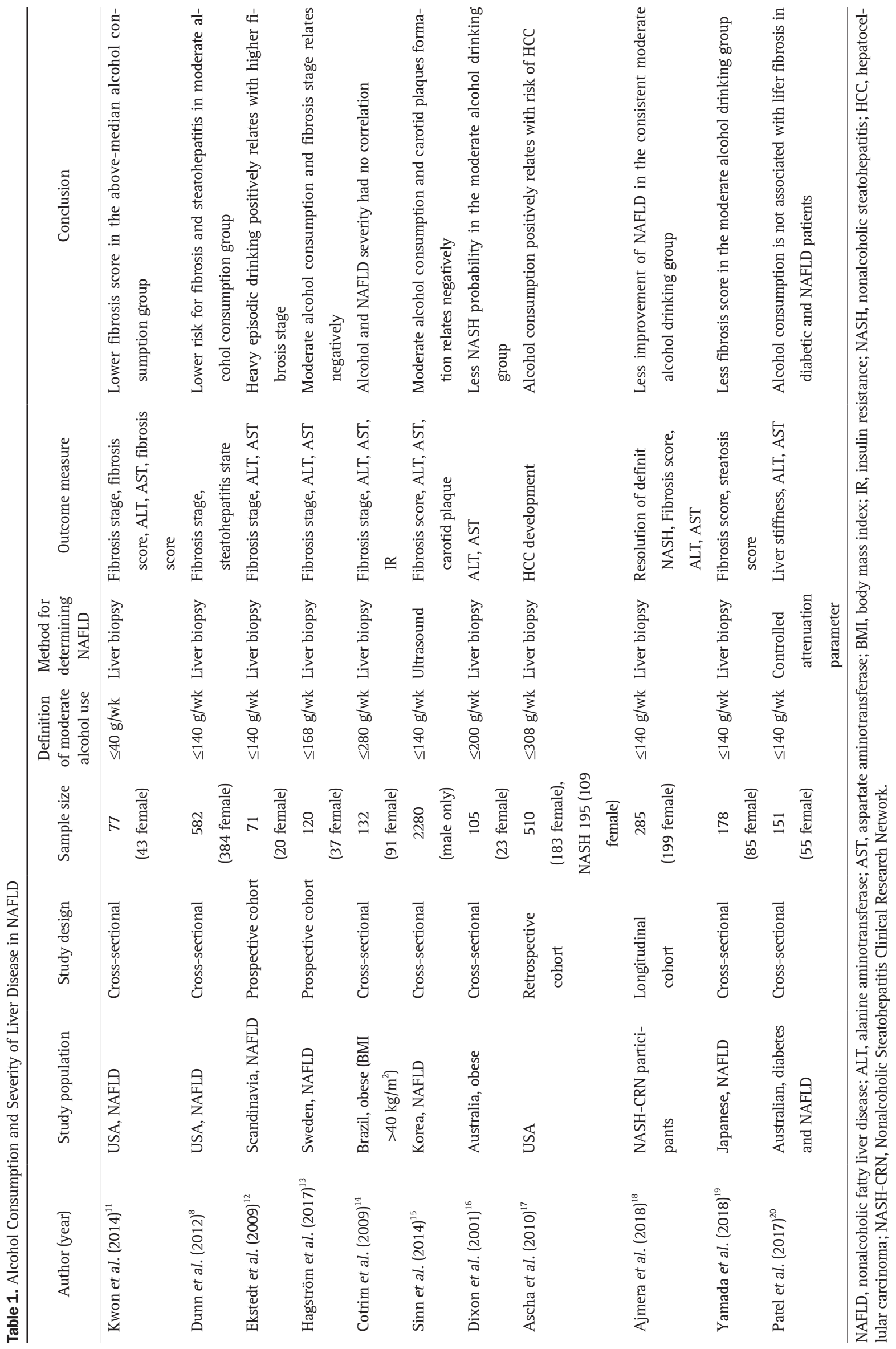


ies. One cohort study suggested a negative correlation between moderate alcohol drinking and fibrosis, ${ }^{13}$ while another cohort study suggested no correlation. ${ }^{12}$ The longitudinal cohort study suggested less improvement of NAFLD in the consistent moderate alcohol drinking group. ${ }^{18}$ The other cohort study suggested even moderate alcohol drinking may exacerbate HCC development. ${ }^{17}$

Three cross-sectional studies suggested that moderate alcohol drinking was negatively associated with the prevalence of NASH and advanced hepatic fibrosis. ${ }^{8,11,19}$ However, four crosssectional studies suggested that moderate alcohol drinking was not associated with NASH progression and fibrosis deterioration. $^{14-16}$

\section{METHOD OF ASSESSING ALCOHOL CONSUMPTION}

Each study used various methods to analyze the alcohol intake of patients (Table 2). Eight studies obtained alcohol intake data through the self-reports of patients, ${ }^{8,11-13,16,18-20}$ and four studies interviewed patients through experts. ${ }^{11,12,14,16}$ Two studies used both the self-report method and the interview method. ${ }^{12,16}$ One study was unclear how alcohol consumption was analyzed. $^{17}$

In most studies, alcohol intake was measured at a specific time point. Two studies used the alcohol use disorder identification test (AUDIT) or AUDIT - consumption (AUDIT-C) questionnaires. ${ }^{8,12,18,20}$ However, AUDIT is intended to identify persons with hazardous and harmful patterns of alcohol consumption. ${ }^{21}$ This questionnaire consists of 10 questions, of which questions 1 to 3 are direct questions about the amount of alcohol consumption. AUDIT-C is a questionnaire that includes only these three questions. Therefore, AUDIT and AUDIT-C have limitations in accurately analyzing the amount or pattern of alcohol consumption. Only four studies included the lifetime drinking history of patients. ${ }^{8,11,13,18}$ A lifetime drinking history questionnaire was designed to record all alcohol consumptions up to the time the patient was asked. The items listed included drinking duration, a frequency of drinking, intake per serving, and type of alcohol. ${ }^{22}$ Including the lifetime drinking history is important because past drinking behavior can alter the patients' current health status.

\section{WHAT IS “MODERATE” ALCOHOL CONSUMPTION?}

The definitions of moderate alcohol consumption were different in each article (Fig. 1). The lowest cutoff was $40 \mathrm{~g} / \mathrm{wk}$, and the highest was $308 \mathrm{~g} / \mathrm{wk}$. The mean was $167 \mathrm{~g} / \mathrm{wk}$. Excluding the outlying lowest cutoff value of Kwon et al., ${ }^{11}$ the mean was $180 \mathrm{~g} / \mathrm{wk}$. The cutoff value for moderate alcohol consumption in most articles ranged between 140 and $200 \mathrm{~g} /$ wk. This is similar to the cutoffs of $210 \mathrm{~g} /$ wk for men and $140 \mathrm{~g} /$ wk for women that distinguish between alcoholic steatohepatitis and NASH. ${ }^{23}$

\section{EFFECTS OF MODERATE ALCOHOL CONSUMPTION ON LIVER FIBROSIS IN NAFLD}

Eight studies showed the relationship between moderate alcohol intake and the degree of fibrosis (Table 3). ${ }^{8,11-13,15,16,18,20}$ Scoring system used to assess the degree of intrahepatic fibrosis were various. Five studies used the NASH Clinical Research Network scoring system for assessing the progression of NASH. Among them, four studies suggested that the level of liver fibrosis was low in patients with moderate alcohol consumption $(\mathrm{p} \leq 0.05),{ }^{8,11,13,19}$ while the other study showed no correlation. ${ }^{18}$

Other three studies used different scoring systems. One study ${ }^{12}$ used the Brunt system to evaluate the degree of NAFLD. ${ }^{24}$ Another study ${ }^{15}$ used NAFLD fibrosis scores without biopsy to evaluate the degree of liver fibrosis. ${ }^{25}$ The other study ${ }^{20}$ used controlled attenuation parameter method to evaluate the degree of liver fibrosis. The three studies showed that moderate alcohol intake and fibrosis severity were not associated. ${ }^{12,15}$

Above finding changed after subgroup analysis according to types of study design. Among the eight studies, five were crosssectional studies. ${ }^{8,11,15,19}$ Three of them showed the negative association between liver fibrosis and moderate alcohol consumption. ${ }^{8,11,19}$ Only one study among the three cohort studies showed the negative association between liver fibrosis and moderate alcohol consumption. ${ }^{12,13,18}$

Interestingly, above finding was related to methods of assessing alcohol consumption. Most studies that evaluated lifetime drinking history suggested a negative association between liver fibrosis and moderate alcohol consumption, ${ }^{8,11,13,19}$ except for one study. $^{18}$

\section{EFFECTS OF MODERATE ALCOHOL CONSUMPTION ON THE PRESENCE OF NASH}

Four studies suggested the effects of moderate alcohol intake on the incidence of intrahepatic inflammation in patients with NAFLD, ${ }^{8,13,16,18}$ however, the results were diverse (Table 4). Alcohol consumption of $<20 \mathrm{~g} /$ day was negatively associated with the incidence of NASH ( $\mathrm{p}=0.0006)$ in a study by Dunn et al. ${ }^{8}$ However, in a study by Hagström et al., ${ }^{13}$ moderate alcohol consumption was not associated with the incidence of NASH. Dixon et al. ${ }^{16}$ reported that moderate alcohol intake was negatively associated with the incidence of NASH in patients with high obesity. Nevertheless, there was no association between alcohol consumption and the incidence of NASH after adjusting for diabetes or insulin resistance. In a study by Ajmera et al., ${ }^{18}$ moderate alcohol drinking was associated with less prevalence of NASH at the baseline. However, after 4 years, consistent moderate drinkers showed less resolution of definite NASH than consistent nondrinkers. 
Table 2. Method of Assessing Alcohol Consumption

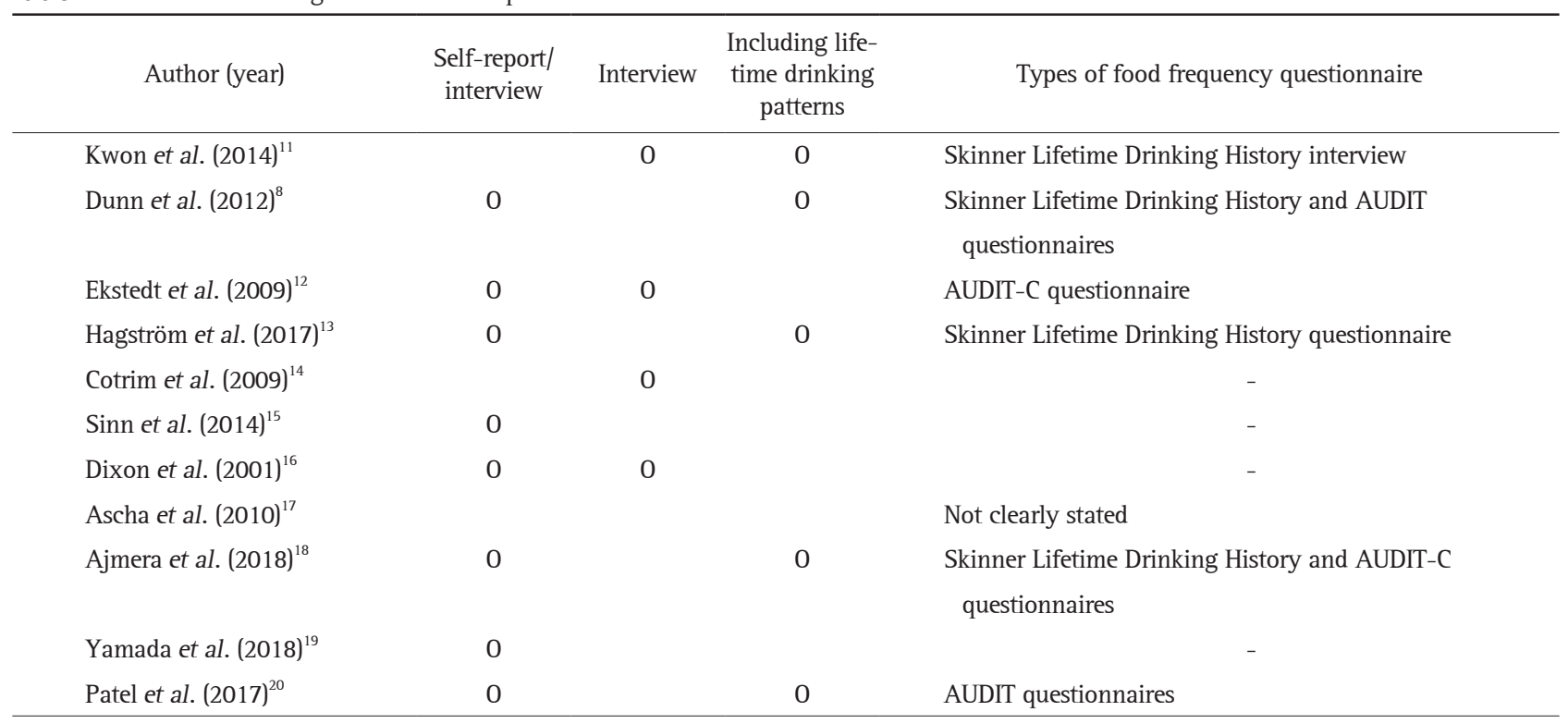

AUDIT, alcohol use disorder identification test; AUDIT-C, alcohol use disorder identification test-consumption.

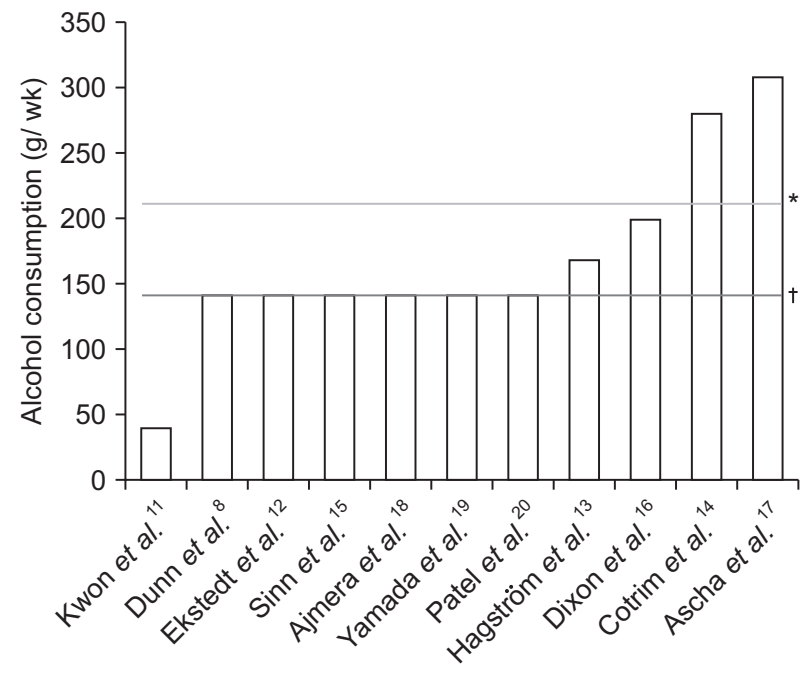

Fig. 1. Definition of moderate alcohol drinking used in each study. *Significant alcohol consumption in men (210 g/wk); 'Significant alcohol consumption in women (140 g/wk).

\section{EFFECTS OF MODERATE ALCOHOL CONSUMPTION ON AMINOTRANSFERASE ACTIVITY IN NAFLD}

Seven articles suggested the relationship between alcohol consumption and alanine aminotransferase (ALT) and aspartate aminotransferase (AST) levels. ${ }^{11,13-15,18-20}$ The AST levels were not different between moderate drinkers and nondrinkers in all seven studies (Table 5). While there was no difference of ALT levels between the two groups in most studies, ALT levels were lower in patients consuming $<20 \mathrm{~g} /$ day of alcohol than in nondrinkers in one study. This study also suggested that ALT and AST levels were higher in patients consuming 20-40 g/day of alcohol. ${ }^{14}$

\section{EFFECTS OF MODERATE ALCOHOL CONSUMPTION ON BIOCHEMICAL PARAMETERS AND CARDIOVASCULAR DISEASE IN NAFLD}

The effect of moderate alcohol intake on cholesterol levels in patients with NAFLD was controversial in the three studies (Supplementary Table 1). ${ }^{11,13,19}$ The triglyceride levels were not significantly different between alcohol drinkers and nondrinkers in the four studies ( $p>0.05)^{8,11,18,19}$ In general, there was no significant difference of high-density lipoprotein (HDL) and homeostasis model assessment of insulin resistance (HOMA-IR) between the two groups. ${ }^{11,13-15,18,19}$

Two studies suggested the relationship between moderate alcohol intake and hypertension in patients with NAFLD (Supplementary Table 2). In one study, the incidence of hypertension in the moderate alcohol user group was lower than that in the nondrinking group, ${ }^{13}$ while the other study suggested a lower incidence of hypertension in the 20-40 g/day alcohol consumption group than in the nondrinking group. ${ }^{14}$ In the study by Sinn et al., ${ }^{15}$ the prevalence of carotid plaques and carotid stenosis were lower in patients with moderate alcohol intake.

\section{DISCUSSION}

In conclusion, moderate alcohol intake in patients with NAFLD has varied results. However, moderate alcohol intake is associated with a low incidence of intrahepatic fibrosis and NASH despite variety and uncertainty on methods of assessing 
Table 3. Effects of Moderate Alcohol Drinking on Liver Fibrosis

\begin{tabular}{|c|c|c|}
\hline Author (year) & Fibrosis & Remarks \\
\hline Kwon et al. $(2014)^{11}$ & $\downarrow$ & $\begin{array}{l}\text { Fibrosis score }(1.2 \pm 1.0 \text { vs } 1.8 \pm 1.2, \mathrm{p}=0.03) \text { among the above-median alcohol consumption versus } \\
\text { below-median alcohol consumption groups }\end{array}$ \\
\hline Dunn et al. $(2012)^{8}$ & $\downarrow$ & $\begin{array}{l}\text { Higher fibrosis stage: } 0 R, 0.56(95 \% \mathrm{CI}, 0.41-0.78 ; \mathrm{p}=0.0005) \text { among moderate alcohol users versus } \\
\text { lifelong nondrinkers }\end{array}$ \\
\hline Ekstedt et al. (2009) ${ }^{12}$ & - & $\begin{array}{l}\text { Fibrosis progression: } \mathrm{OR}, 1.012(95 \% \mathrm{CI}, 1.000-1.025 ; \mathrm{p}=0.055) \text { among alcohol users versus nondrink- } \\
\text { ers }\end{array}$ \\
\hline Hagström et al. $(2017)^{13}$ & $\downarrow$ & $\begin{array}{l}\text { Higher fibrosis stage: } \mathrm{OR}, 0.86(95 \% \mathrm{CI}, 0.77-0.97 ; \mathrm{p}=0.016) \text { among the above-median alcohol con- } \\
\text { sumption versus below-median alcohol consumption groups }\end{array}$ \\
\hline Sinn et al. $(2014)^{15}$ & - & Fibrosis score $(-1.9$ vs $-1.9 ; \mathrm{p}=0.93)$ among moderate alcohol drinkers versus nondrinkers \\
\hline Ajmera et al. (2018) ${ }^{18}$ & - & $\begin{array}{l}\text { Change in fibrosis score }(0.08 \pm 0.16 \text { vs } 0.06 \pm 0.18 ; \mathrm{p}=0.85) \text { among moderate alcohol drinkers versus } \\
\text { nondrinkers }\end{array}$ \\
\hline Yamada et al. $(2018)^{19}$ & $\downarrow$ & $\begin{array}{l}\text { Fibrosis score: OR, } 0.707 \text { (95\% CI, 0.512-0.977; } \mathrm{p}=0.035) \text { among moderate alcohol users versus lifelong } \\
\text { nondrinkers }\end{array}$ \\
\hline Patel et al. $(2017)^{20}$ & - & $\begin{array}{l}\text { Liver stiffness measurement over } 0.82 \mathrm{kPa} \text { : OR, } 0.91 \text { (95\% CI, 0.27-3.10; } \mathrm{p}=0.881 \text { ) among moderate } \\
\text { alcohol users versus lifelong nondrinkers }\end{array}$ \\
\hline
\end{tabular}

OR, odds ratio; $\mathrm{CI}$, confidence interval.

Table 4. Effects of Moderate Alcohol Drinking on NASH

\begin{tabular}{|c|c|c|}
\hline Author (year) & NASH & Remarks \\
\hline Dunn et al. (2012) ${ }^{8}$ & $\downarrow$ & $\begin{array}{l}\text { NASH: OR, } 0.52 \text { (95\% CI, 0.36-0.76; } \mathrm{p}=0.0006) \text { among moderate alcohol users versus lifelong non- } \\
\text { drinkers }\end{array}$ \\
\hline Hagström et al. (2017) ${ }^{13}$ & - & $\begin{array}{l}\text { NASH: OR, } 0.98 \text { (95\% CI, 0.86-1.11; } \mathrm{p}=0.71) \text { among the above-median alcohol consumption versus } \\
\text { below-median alcohol consumption groups }\end{array}$ \\
\hline \multirow[t]{2}{*}{ Dixon et al. $(2001)^{16}$} & $\downarrow$ & $\begin{array}{l}\text { NASH: OR, } 0.35 \text { (95\% CI, 0.12-1.0; } p=0.040 \text { ) among moderate alcohol users versus lifelong non- } \\
\text { drinkers before adjusting for diabetes or insulin resistance }\end{array}$ \\
\hline & - & NASH after adjusting for diabetes or insulin resistance \\
\hline \multirow[t]{2}{*}{ Ajmera et al. (2018) ${ }^{18}$} & $\downarrow$ & $\begin{array}{l}\text { Definite NASH prevalence at the baseline ( } 57 \% \text { vs } 74 \%, p=0.01 \text { ) among moderate alcohol users ver- } \\
\text { sus lifelong nondrinkers }\end{array}$ \\
\hline & $\uparrow$ & $\begin{array}{l}\text { Resolution of definite NASH after } 4 \text { years: difference in adjusted mean change, } 0.32 \text { (95\% CI, 0.11- } \\
0.92 ; \mathrm{p}=0.04 \text { ) among consistent moderate drinkers and consistent nondrinkers }\end{array}$ \\
\hline
\end{tabular}

NASH, nonalcoholic steatohepatitis; OR, odds ratio; CI, confidence interval.

alcohol consumption.

Several studies demonstrated possible mechanisms for beneficial effects of moderate alcohol consumption. In the animal study by Kanuri et al., ${ }^{26}$ moderate alcohol drinking was associated with lower inflammation in liver. The hepatoprotective property was associated with an induction of the sirtuin-1/adiponectin-signaling cascade in visceral fat tissue and activation of protein kinase B in the liver. Wang and his coworkers found that moderate alcohol intake induces thermogenic brown/beige adipocyte formation and promotes glucose and lipid oxidation via elevating retinoic acid signaling. ${ }^{27}$ This resulted in the prevention of high-fat-diet-induced obesity and metabolic dysfunction. Yamada et al. ${ }^{19}$ evaluated the effects of light alcohol consumption on gene expression in the liver. The moderate al- cohol drinking was associated with lowered expression of Tolllike receptor 4, nuclear factor-kappa beta and more genes which are involved in immune response pathways.

Yet, it may be early to recommend drinking to patients with NAFLD. Firstly, there were no randomized control trials and all studies were cross-sectional studies or cohort studies. Secondly, the effect of alcohol intake on liver cancer in patients with NAFLD is controversial. Among the 11 journals we reviewed, only one journal analyzed the effect of moderate alcohol drinking on the risk of HCC. ${ }^{17}$ The study used $308 \mathrm{~g} / \mathrm{wk}$ as a cutoff value for the definition of moderate alcohol drinking. This is a much higher value compared to other journals we reviewed since the average was $167 \mathrm{~g} / \mathrm{wk}$. More clinical data is needed to further analyze the effect of moderate alcohol drinking on HCC 
Table 5. Effects of Moderate Alcohol Drinking on ALT/AST

\begin{tabular}{|c|c|c|c|c|}
\hline Author (year) & ALT & Conclusion, IU/L & AST & Conclusion, IU/L \\
\hline Kwon et al. $(2014)^{11}$ & - & $\begin{array}{l}78 \pm 37 \text { vs } 73 \pm 59, \mathrm{p}=0.68 \text {; among the above-median alcohol } \\
\text { consumption versus below-median alcohol consumption } \\
\text { groups }\end{array}$ & - & $50 \pm 24$ vs $56 \pm 43, p=0.44$ \\
\hline Hagström et al. $(2017)^{13}$ & - & $\begin{array}{l}61 \text { vs } 55, p=0.22 \text {; among moderate alcohol drinkers versus } \\
\text { below-median drinkers }\end{array}$ & - & 44 vs $44, p=0.76$ \\
\hline Cotrim et al. (2009) ${ }^{14}$ & $\downarrow$ & $\begin{array}{l}48 \text { vs } 30 \text { vs 35; among G1 (20-40 g/day) vs G2 (0-20 g/day) } \\
\text { vs G3 (nondrinkers) }\end{array}$ & - & 30 vs 23 vs 24 \\
\hline Sinn et al. $(2014)^{15}$ & - & $\begin{array}{l}29 \text { vs } 28, \mathrm{p}=0.11 \text {; among moderate alcohol drinkers versus } \\
\text { nondrinkers }\end{array}$ & - & 24 vs $24, p=0.85$ \\
\hline Ajmera et al. (2018) ${ }^{18}$ & - & $\begin{array}{l}62 \text { vs 57, } \mathrm{p}=0.08 \text {; among moderate alcohol drinkers versus } \\
\text { nondrinkers }\end{array}$ & - & 43 vs $42, p=0.37$ \\
\hline Yamada et al. (2018) ${ }^{19}$ & - & $\begin{array}{l}68.5 \pm 49.8 \text { vs } 64.1 \pm 79.8, p=0.0610 ; \text { among moderate alcohol } \\
\text { drinkers versus nondrinkers }\end{array}$ & - & $40.1 \pm 22.9$ vs $46.1 \pm 42.6, p=0.6993$ \\
\hline Patel et al. $(2017)^{20}$ & - & $\begin{array}{l}36.4 \pm 26.4 \text { vs } 38.4 \pm 29.5 \text { vs } 37.4 \pm 15.8 \text {; among nondrinkers } \\
\text { versus light drinkers versus moderate drinkers }\end{array}$ & - & $29.0 \pm 17.6$ vs $28.6 \pm 26.1$ vs $24.7 \pm 11.2$ \\
\hline
\end{tabular}

ALT, alanine aminotransferase; AST, aspartate aminotransferase.

development in the patient with NAFLD. Thirdly, the methods used for assessing alcohol consumption have many limitations. Fourthly, the longitudinal cohort study suggested that the modest alcohol use is associated with less improvement of NASH. ${ }^{18}$ Lastly, the amount of moderate alcohol consumption defined in each article was different. Clinical data are still lacking, and the conclusion cannot be drawn on how much alcohol is appropriate for each individual patient. Additional studies should be undertaken on the analysis of adequate alcohol intake, patterns of intake, and positive and negative effects.

\section{CONFLICTS OF INTEREST}

No potential conflict of interest relevant to this article was reported.

\section{ACKNOWLEDGEMENTS}

Author contributions: guarantor of the article, D.W.J. D.W.J. contributed to the study design. I.K. wrote the manuscript. J.H.M. contributed to critical review and manuscript polishing.

\section{REFERENCES}

1. Wang LY, You SL, Lu SN, et al. Risk of hepatocellular carcinoma and habits of alcohol drinking, betel quid chewing and cigarette smoking: a cohort of 2416 HBsAg-seropositive and $9421 \mathrm{HBsAg}-$ seronegative male residents in Taiwan. Cancer Causes Control 2003;14:241-250.

2. Jee SH, Ohrr H, Sull JW, Samet JM. Cigarette smoking, alcohol drinking, hepatitis B, and risk for hepatocellular carcinoma in Ko- rea. J Natl Cancer Inst 2004;96:1851-1856.

3. Chen CJ, Yang HI, Su J, et al. Risk of hepatocellular carcinoma across a biological gradient of serum hepatitis B virus DNA level. JAMA 2006;295:65-73.

4. Iida-Ueno A, Enomoto M, Tamori A, Kawada N. Hepatitis B virus infection and alcohol consumption. World J Gastroenterol 2017;23:2651-2659.

5. Sogabe M, Okahisa T, Nakagawa T, et al. Influence of light alcohol consumption on lifestyle-related diseases: a predictor of fatty liver with liver enzyme elevation in Japanese females with metabolic syndrome. BMC Gastroenterol 2016;16:17.

6. Liu P, Xu Y, Tang Y, et al. Independent and joint effects of moderate alcohol consumption and smoking on the risks of nonalcoholic fatty liver disease in elderly Chinese men. PLoS One 2017;12:e0181497.

7. Roerecke M, Nanau R, Rehm J, Neuman M. Ethnicity matters: a systematic review and meta-analysis of the non-linear relationship between alcohol consumption and prevalence and incidence of hepatic steatosis. EBioMedicine 2016;8:317-330.

8. Dunn W, Sanyal AJ, Brunt EM, et al. Modest alcohol consumption is associated with decreased prevalence of steatohepatitis in patients with non-alcoholic fatty liver disease (NAFLD). J Hepatol 2012;57:384-391.

9. Ajmera VH, Terrault NA, Harrison SA. Is moderate alcohol use in nonalcoholic fatty liver disease good or bad? A critical review. Hepatology 2017;65:2090-2099.

10. Boyle M, Masson S, Anstee QM. The bidirectional impacts of alcohol consumption and the metabolic syndrome: cofactors for progressive fatty liver disease. J Hepatol 2018;68:251-267.

11. Kwon HK, Greenson JK, Conjeevaram HS. Effect of lifetime alcohol consumption on the histological severity of non-alcoholic 
fatty liver disease. Liver Int 2014;34:129-135.

12. Ekstedt M, Franzén LE, Holmqvist M, et al. Alcohol consumption is associated with progression of hepatic fibrosis in non-alcoholic fatty liver disease. Scand J Gastroenterol 2009;44:366-374.

13. Hagström H, Nasr P, Ekstedt M, et al. Low to moderate lifetime alcohol consumption is associated with less advanced stages of fibrosis in non-alcoholic fatty liver disease. Scand J Gastroenterol 2017;52:159-165.

14. Cotrim HP, Freitas LA, Alves E, Almeida A, May DS, Caldwell S. Effects of light-to-moderate alcohol consumption on steatosis and steatohepatitis in severely obese patients. Eur J Gastroenterol Hepatol 2009;21:969-972.

15. Sinn DH, Gwak GY, Cho J, et al. Modest alcohol consumption and carotid plaques or carotid artery stenosis in men with nonalcoholic fatty liver disease. Atherosclerosis 2014;234:270-275.

16. Dixon JB, Bhathal PS, O’Brien PE. Nonalcoholic fatty liver disease: predictors of nonalcoholic steatohepatitis and liver fibrosis in the severely obese. Gastroenterology 2001;121:91-100.

17. Ascha MS, Hanouneh IA, Lopez R, Tamimi TA, Feldstein AF, Zein NN. The incidence and risk factors of hepatocellular carcinoma in patients with nonalcoholic steatohepatitis. Hepatology 2010;51:1972-1978.

18. Ajmera V, Belt P, Wilson LA, et al. Among patients with nonalcoholic fatty liver disease, modest alcohol use is associated with less improvement in histologic steatosis and steatohepatitis. Clin Gastroenterol Hepatol 2018;16:1511-1520.

19. Yamada K, Mizukoshi E, Seike T, et al. Light alcohol consumption has the potential to suppress hepatocellular injury and liver fibrosis in non-alcoholic fatty liver disease. PLoS One 2018;13:e0191026.

20. Patel PJ, Smith D, Connor JP, et al. Alcohol consumption in diabetic patients with nonalcoholic fatty liver disease. Can J Gastroenterol Hepatol 2017;2017:7927685.

21. Babor TF, Higgins-Biddle JC, Saunders JB, Monteiro MG, WHO. AUDIT: the alcohol use disorders identification test. Guidelines for use in primary health care. 2nd ed. Geneva: WHO, 2001.

22. Skinner H. Lifetime drinking history: administration and scoring guidelines. Toronto: Addiction Research Foundation, 1979.

23. Chalasani N, Younossi Z, Lavine JE, et al. The diagnosis and management of non-alcoholic fatty liver disease: practice Guideline by the American Association for the Study of Liver Diseases, American College of Gastroenterology, and the American Gastroenterological Association. Hepatology 2012;55:2005-2023.

24. Brunt EM, Janney CG, Di Bisceglie AM, Neuschwander-Tetri BA, Bacon BR. Nonalcoholic steatohepatitis: a proposal for grading and staging the histological lesions. Am J Gastroenterol 1999;94:2467-2474.

25. Angulo P, Hui JM, Marchesini G, et al. The NAFLD fibrosis score: a noninvasive system that identifies liver fibrosis in patients with NAFLD. Hepatology 2007;45:846-854.

26. Kanuri G, Landmann M, Priebs J, et al. Moderate alcohol consumption diminishes the development of non-alcoholic fatty liver disease (NAFLD) in ob/ob mice. Eur J Nutr 2016;55:1153-1164.

27. Wang B, Wang Z, de Avila JM, et al. Moderate alcohol intake induces thermogenic brown/beige adipocyte formation via elevating retinoic acid signaling. FASEB J 2017;31:4612-4622. 